NASA Technical Memorandum 86955

\title{
Vacuum Chamber Pressure Effects on Thrust Measurements of Low Reynolds Number Nozzles
}

James S. Sovey, Paul F. Penko, Stanley P. Grisnik, and Margaret V. Whalen

Lewis Research Center

Cleveland, Ohio

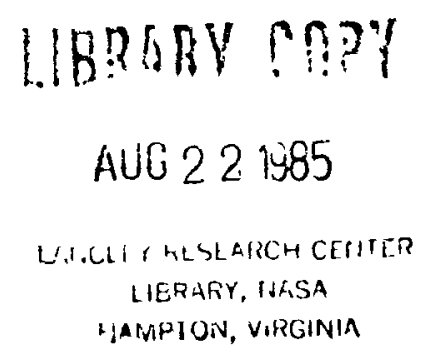

Prepared for the 1985 JANNAF Propulsion Meeting sponsored by the JANNAF Interagency Propulsion Committee San Diego, California, April 9-12, 1985

\section{N/SA}




\section{VACUUM CHAMBER PRESSURE EFFECTS ON THRUST MEASUREMENTS}

OF LOW REYNOLDS NUMBER NOZZLES

James S. Sovey, Paul F. Penko, Stanley P. Grisnik, and Margaret V. Whalen National Aeronautics and Space Administration

Lew1s Research Center

Cleveland, Oh10 44135

\section{ABSTRACT}

Tests were conducted to investigate the effect of vacuum-facility pressure on the performance of small-thruster nozzles. Thrust measurements of two converging-diverging nozzles with an area ratio of 140 and an orifice plate flowing unheated nitrogen and hydrogen were taken over a wide range of vacuum facility pressures and nozzle throat Reynolds numbers. In the Reynolds number range of 2200 to 12000 there was no discernable viscous effect on thrust below an ambient-to-total-pressure ratio of $10^{-3}$. In nearly all cases, flow separation occurred at a pressure ratio of about $10^{-3}$. This was the upper limit for obtaining an accurate thrust measurement for a conical nozzle with an area ratio of 140 .

\section{NOMENCLATURE}

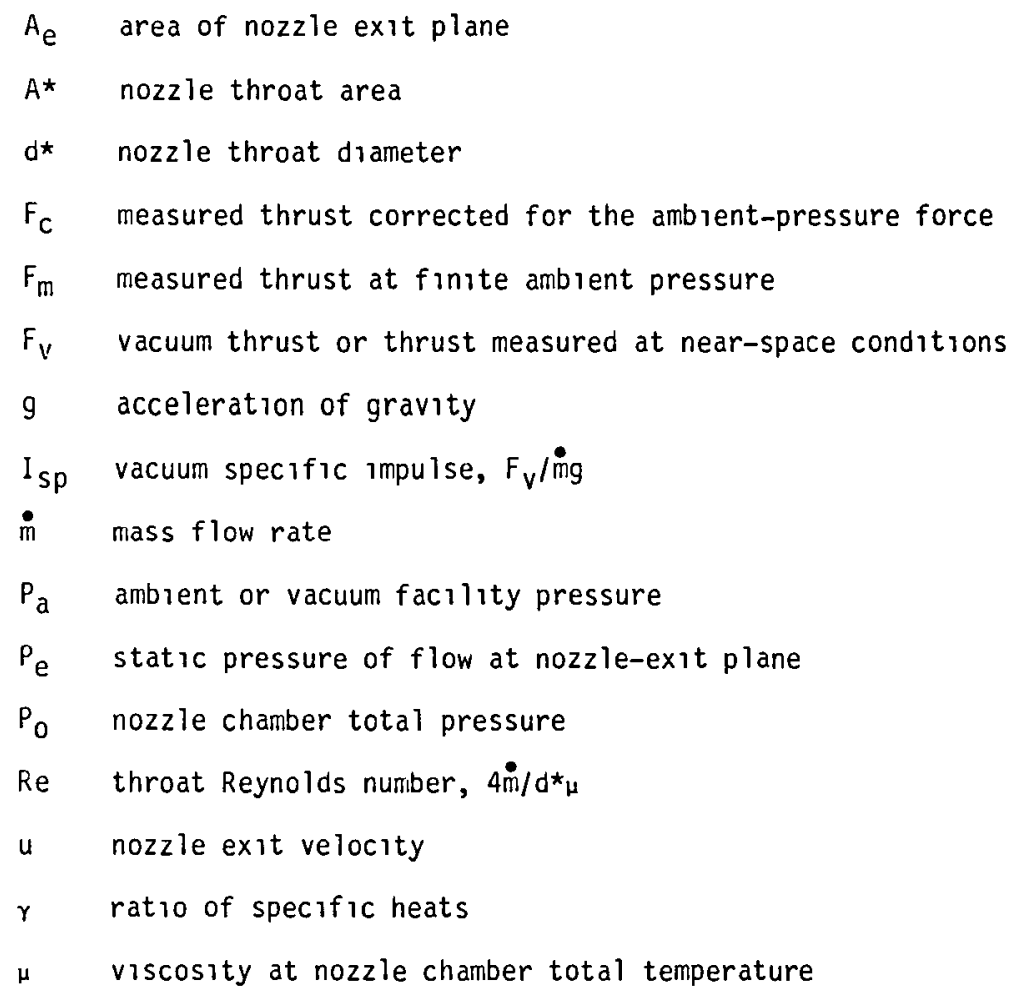

INTRODUCTION

North South station-keeping of many satelintes is being met using thrusters in the 0.2 to 0.4 $N$ thrust range. Performance calibration of these thrusters is generally undertaken in vacuum facilities with ambient pressures in the range of a few hundred micrometers of mercury. Relatively high propellant flow rates usually preclude the use of diffusion pumps and large cryo-pumped facilities are not widely avallable.

The thrust measured in a finite ambient pressure, assuming uniform properties at the nozzle exit, is given by

$$
F_{m}=\dot{m u}+\left(P_{e}-P_{a}\right) A_{e},
$$

and the thrust in vacuum is

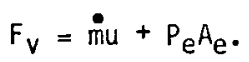

Approvea for public release, distribution is unlimited. 
Therefore the thrust measured in a finite ambient pressure corrected to vacuum conditions is given by

$$
F_{c}=F_{m}+P_{a} A_{e} \text {. }
$$

Equation (3) should yield the correct space-vacuum thrust providing that the ratio of ambient pressure to nozzle inlet total pressure $\left(P_{a} / P_{0}\right)$ is sufficiently low so that shock waves are not present in the nozzle. Furthermore, in the case of low Reynolds number flow, the ambient pressure must be sufficiently low so that it does not influence the nozzle flow field.

With low Reynolds number (Re) nozzle flow, several investigators ${ }^{1-3}$ have found significant variation in thrust over a range of vacuum facility pressure from about $1 \times 10^{-4}$ to 1 torr where the range $f_{f} P_{a} / P_{0}$ was well below the point where shocks would be present. Page et al. $P_{\text {and }}$ Yoshida et al.2,3 found an appreciable variation in thrust with vacuum chamber pressure using hydrogen and ammonia resistojets. In their work, a 17 to 19 percent degradation in thrust occurred when the ambient pressure was varied from about $5 \times 10^{-4}$ to 1 torr after accounting for the ambient pressure force over the nozzle exit as well as recirculation effects in the vacuum chamber. Their $45 \mathrm{mN}$ hydrogen and ammonia resistojets were operated at throat Reynolds numbers of 400 and 800 , respectively. They conjectured that the vacuum chamber pressure affected the nozzle flow through the subsonic boundary layer.

Rothe 4 did a detalled investigation of low-Reynolds number nozzle flow over a Reynolds number range of 50 to 780 . He measured density and temperature distributions in the nozzle flow field using an electron-beam method. He also determined shock patterns and flow separation by flow visualization. His tests were conducted with unheated nitrogen flowing through two conical nozzles, each of $20^{\circ}$ half-angle and area ratio $\left(A_{e} / A^{\star}\right)$ of 66 , and each having a different throat diameter. Rothe's data showed that at a Reynolds number of 50 , the flow on the nozzle axis decelerated to slightly less than Mach 1 at the exit plane. Density profiles at various axial stations in the nozzle illustrated that the flow was fully viscous with no evidence of an inviscid core. At a Reynolds number of 300 , the flow was characterized by a narrow inviscid core enveloped by a thick viscous outer layer that extended to the walls. The inviscid core gradually dissipated until it was no longer evident at the exit plane. The flow on the axis remained supersonic.

In investigating the effect of ambient pressure on the flow, Rothe showed that at a Reynolds number of 780, an ambient-to-total-pressure ratio of $3 \times 10^{-3}$ was not enough to maintain full flow in the nozzle. A barrel-shaped shock was present upstream of the nozzle exit and the flow was separated from the wall. As the ambient pressure was raised, the separation point moved further into the nozzle.

Rothe's investigation showed that low-Reynolds-number flow in a converging-diverging nozzle is characterized by a large subsonic outer region and a narrow supersonic core. Hence at low Reynolds numbers the ambient pressure could concelvably affect the flow through this large subsonic region and may explain the effect exhibited in Refs. 1 to 3. Rothe's work also showed that as the Reynolds number was increased, the flow more closely resembled isentropic flow and that shock waves were present when the flow had to adjust to a high ambient pressure.

To further investigate the effects of ambient pressure on low-Reynolds number nozzle flow and the implications of testing small thrusters in a finite ambient pressure, tests were conducted with several nozzles on unheated nitrogen and hydrogen over a Reynolds number range of 700 to 12000 . Nozzle thrust was measured at various vacuum facility pressures ranging from $3 \times 10^{-4}$ to 1 torr. The measured yalues of thrust corrected for the ambient-pressure force were compared to the deepvacuum ( $3 \times 10^{-4}$ torr) value in an attempt to investigate the range of Reynolds numbers where the ambient pressure might have a significant effect on thrust as exhibited in Refs. 1 through 3 . An attempt was also made to investigate the effect of Reynolds number on the point where the flow begins to separate within the nozzle from the onset of a shock wave. This effort was undertaken to help def ine where thruster test data taken in a finite ambient pressure can be accurately corrected to space-vacuum conditions.

\section{APPARATUS AND PROCEDURE}

Two converging-diverging nozzles and an orifice plate were used in the tests. Table I lists their dimensions, pressures, and flow rates. Nozzle $A_{5}$ was similar to the nozzle on the TRW $H i g h$ Performance Electrothermal Hydrazine Thruster (HIPEHT) ${ }^{5}$ and had an area ratio of 147 . Nozzle B had a relatively large throat diameter and was operated at nearly the same flow rates as nozzle $A$ to achieve lower throat Reynolds numbers. Nozzle B initially had an area ratio of 140 and was cut down to an area ratio of 38 for subsequent tests. The orifice plate had a conical inlet with a $45^{\circ}$ half-angle.

Thrust measurements were made on a thrust stand that consisted of a horizontal mounting plate supported by four flexure plates. 5 Force in the horizontal direction either from thrust or application of calibration weights was measured by a strain-gage load cell. Propellant was fed to the 
thrust stand in a $3.2 \mathrm{~mm}(1 / 8 \mathrm{ln})$ diameter, thin-wall, stainless steel tube that acted as a fifth flexure. Thrust-stand tares were highly reproducible and load-cell drift was insignificant for operation with unheated propellants. The estimated precision of the thrust measurement is about $\pm 0.4 \mathrm{mN}$. The uncertainty in the thrust measurement ranged from \pm 0.5 percent at $75 \mathrm{mN}$ to $\pm 1.7 \mathrm{percent}$ at $22 \mathrm{mN}$ which was the range of thrust values for the tests.

Windage effects, or the circulation of gases in the test facility, produced a thrust-stand deflection opposing the direction of nozzle thrust. Some of the thrust stand members apparently act as a "sall" in the circulating gas environment. 1 The windage effect was examined by flowing gas through the orifice plate which was located very near but disconnected from the thrust stand mounting plate. Thrust stand deflections were monitored, at the flow rates of interest, over a vacuum facility pressure range of $10^{-4}$ to 10 torr. The largest windage effects occurred at an ambient pressure of about 0.05 torr. The maximum thrust correction for windage was 1.5 percent for nitrogen and 3 percent for hydrogen. The windage corrections at ambient pressures less than $1 \times 10^{-3}$ torr and greater than 0.3 torr were always less than 1 percent.

Gas flow rates were measured with mass-flow-rate transducers which used a heated capillary tube to relate thermal changes to mass flow rate and the gas heat capacity. The flow tranducers were calibrated with either air or nitrogen using a volume displacement method. A flow rate calibration for hydrogen was obtained using gas conversion factors supplied by the transducer vendor. Thus a greater uncertainty exists in the hydrogen flow rate measurement.

The chamber pressure for nozzle B was directly measured. The chamber pressure for nozzle A was assumed to be between the line pressure and the minimum chamber pressure calculated assuming a thrust coefficient, $F_{V} / P_{0} A^{*}$, of 1.6 . A value of 1.6 was based on analysis and experiment from Refs. 6 and 7.

The tests were conducted in a vacuum chamber measuring $4.6 \mathrm{~m}$ in diameter by $19 \mathrm{~m} \mathrm{long} 8$. The pumping system is comprised of 20 oll diffusion pumps with four lobe-type blowers installed in parallel, followed by four rotating piston-type roughing pumps. Vacuum chamber pressures in the vicin1 ty of the thrust stand were measured with a hot cathode ionization gauge for pressures less than $3 \times 10^{-4}$ torr, a cold cathode gauge from $10^{-4}$ to 0.2 torr, an Alphatron gauge from $10^{-2}$ to 0.5 torr, and a bourdon-tube gauge for pressures greater than 0.5 torr. The indicated pressures were corrected for gauge sensitivity to propeliant type. The uncertainty in the ambient pressure $\left(P_{a}\right)$ measurement below 0.5 torr was estimated to be less than \pm 20 percent. The uncertainty in the pressure ratio $\left(P_{a} / P_{0}\right)$ for nozzle $A$ was less than \pm 40 percent and nozzle $B, \pm 20$ percent.

A typical plot of thrust versus ambient pressure for nozzle $A$ flowing hydrogen is shown in Fig. 1. The open symbols are the direct thrust measurements, $F_{m}$, and the solid symbols are $F_{m}$ corrected for the ambient pressure force.

The diffusion pumps could maintain operation at pressures up to $4 \times 10^{-4}$ torr for $0.1 \mathrm{~g} / \mathrm{s}$ of $\mathrm{n}$ itrogen and $9 \times 10^{-4}$ torr for the $0.03 \mathrm{~g} / \mathrm{s}$ of hydrogen. A flow rate of $0.1 \mathrm{~g} / \mathrm{s}$ of nitrogen corresponded to a thrust of about $70 \mathrm{mN}$.

\section{RESULTS AND DISCUSSION}

The ratio of measured-to-vacuum thrust for the two converging-diverging nozzles is presented for throat Reynolds numbers of 700 to 12000 as a function of $P_{a} / P_{0}$. Since $m, d^{\star}, P_{a}$, and $P_{0}$ were all varied, it was necessary to choose $R e$ and $P_{a} / P_{0}$ as the independent variables. Measured thrust refers to the thrust measured at a particular vacuum chamber or ambient pressure. Vacuum thrust is defined as the thrust measured at deep vacuum $\left(\mathrm{P}_{\mathrm{a}}<5 \times 10^{-4}\right.$ torr $)$.

For reference, thrust measurements with the orifice plate were taken over a range of ambient pressures. The ambient pressure had no effect on the thrust measurements. For nitrogen, the thrust varied less than \pm 2 percent over the range of pressure ratios of $10^{-6}$ to $10^{-3}$. The thrust was nominally $42 \mathrm{mN}$ at a flow rate of $0.0786 \mathrm{~g} / \mathrm{s}$.

Figures 2 and 3 show the effect of ambient pressure on thrust for nozzle A. Figure 2 shows the data taken with hydrogen and $\mathrm{Fig}$. 3 the data with nitrogen. The open symbols are the actual measurements and the solid symbols are the measurements corrected for the ambient-pressure force. At pressure ratios less than $3 \times 10^{-5}$ the ambient-pressure force 15 negligible. At Reynolds numbers from 2000 to 12000 there is no discernable viscous effect on thrust below an ambient-to-total pressure ratio of $1 \times 10^{-3}$. Below this pressure ratio the corrected thrust is generally within \pm 2 percent of the vacuum thrust.

In the case where a shock stands in the nozzle, the thrust ratio $\left(F_{c} / F_{V}\right)$ will be greater than 1.0 when $F_{m}$ is corrected using the actual nozzle exit area. In this case, the nozzle has an effective area less than the geometrical exit area and $F_{m}$ is thus overcorrected. The criteria 
that was used to determine the onset of flow separation, or the point where a shock moves into the nozzle, was the point where $F_{c} / F_{V}$ just started to exceed 1.0 . This point was considered the upper 1 imit for testing a nozzle designed for supersonic operation in space since the thrust measured at higher pressure ratios cannot be corrected to vacuum conditions. Data at pressure ratios higher than the point where $F_{C} / F_{V}>1.0$ were consequently not of interest in this investigation.

From the solid symbols in Figs. 2 and 3 it appears that flow separation sets in at about a pressure ratio of $10^{-3}$, independent of the Reynolds number. This correlates with Rothe's observations for flow at a Reynolds number of 780. As a point of reference, from simple isentropic-flow calculations, a shock will stand at the exit of a nozzle with an area ratio ( $\left.A_{e} / A^{*}\right)$ of 140 at a pressure ratio of about $10^{-2}$.

Figures 4 and 5 display the ratio of measured-to-vacuum thrust for nozzle $B$ as a function of pressure ratio. For nozzle $B$ the Reynolds number ranged from 680 to 3700 . In the case of nozzle $B$ there is insufficient data to discern any viscous effect on thrust at pressure ratios below the point of separation. The vacuum facility could not provide a diffusion-pumped environment at pressure ratios of interest because of the relatively high flow rates in the nozzle. The point of flow separation appears to occur at about the same point as for the higher Reynolds number flows of nozzle A.

When nozzle $B$ was çut down to an area ratio of $38: 1$, flow separation occurred at a higher pressure ratio, about $3 \times 10^{-3}$ (not shown in the figures). As expected a higher pressure ratio was required to cause a shock in the nozzle of lower area ratio.

Figure 6 contains most of the data from Figs. 2 to 5 in a plot of thrust ratio versus pressure ratio. Also shown is the isentropic-flow calculation of $F_{m} / F_{v}$ as a function of $P_{a} / P_{0}$ for an area ratio of 140 . For $10^{-4}<\mathrm{Pa}_{\mathrm{a}} / \mathrm{P}_{\mathrm{o}}<10^{-3}$, the calculated values of $F_{\mathrm{m}} / \mathrm{F}_{\mathrm{v}}$ are generally 4 to 9 percent higher than the measured values. The difference between the calculated and measured values may be attributed to the relatively large uncertainty in $P_{a} / P_{0}$. At values of $P_{a} / P_{p}>10^{-3}$ a shock stands in the nozzle and the isentropic calculation of $F_{m} / F_{v}$ is no longer valid as the calculation was not carried through a shock.

\section{CONCLUDING REMARKS}

Thrust measurements of two converging-diverging nozzles and an orifice plate flowing unheated nitrogen and hydrogen were taken over a wide range of vacuum facility pressures and nozzle-throat Reynolds numbers. The purpose of the tests was to investigate the effect of vacuum facility pressure as a function of Reynolds number on the performance of small nozzles designed to operate in space vacuum.

In the Reynolds number range of 2200 to 12000 there was no discernable viscous effect on thrust below an ambient-to-total pressure ratio of $10^{-3}$. In nearly all cases, flow separation occurred at a pressure ratio of about $1 \times 10^{-3}$. This was the upper 1 imit for obtaining an accurate thrust measurement with the conical nozzles having an area ratio of 140. Tests with a nozzle of smaller area ratio moved this point to a slightly higher pressure ratio since a higher ambient pressure would be required to cause a shock to move into the nozzle.

Further investigation of the viscous effect on thrust will require that additional tests be performed using heated flow at lower flow rates to achieve lower Reynolds numbers and ambient pressures than reported in this paper. The sensitivity of flow separation to nozzle area ratio and contour is also of interest, and further testing is required to fully understand that important relationship.

\section{REFERENCES}

1. Page, Russell J., et al.: Life Test of S1x High Temperature Resistojets. AIAA Paper 69-294, Mar. 1969.

2. Yoshida, R.Y., et a1.: Resistojet Thruster Life Tests and High Vacuum Performance. (TMC-S-974, Marquardt Corp.; NASA Contract NAS1-8090.) NASA CR-66970, 1970.

3. Yoshida, Ronald Y.; Halbach, Carl R.; and Hill, C. Scott: Life Test Summary and High-Vacuum Tests of 10-mlb Resistojets. J. Spacecr. Rockets, vol. 8, no. 4, Apr. 1971, pp. 414-416.

4. Rothe, Dietmar E.: Electron-Beam Studies of Viscous Flow in Supersonic Nozzles. AIAA J. vol. 9, no. 5, May 1971, pp. 804-811.

5. Zafran, S.; and Jackson, B.: Electrothermal Thruster Dragnostics, Vol. II. (TRW-39152-6012-UE-00-Vo?-2, TRW; NASA Contract NAS3-23265.) NASA CR-168174-Vol-2, 1983. 
6. Spisz, Ernie W.; Brinich, Paul F.; and Jack, John R.: Thrust Coefficients of Low-Thrust Nozzles. NASA TN-D-3056, 1965.

7. Rae, William J.: Some Numerical Results on Viscous Low-Density Nozzle Flows in the SlenderChannel Approximation. AIAA J., vol. 9, no. 5, May 1971, pp. 811-820.

8. Finke, Robert C.; Holmes Arthur D.; and Keller, Thomas A.: Space Environment Facility for Electric Propulsion Systems Research. NASA TN-D-2774, 1965. 
TABLE I. - THRUSTER AND ORIFICE PLATE PARAMETERS

\begin{tabular}{|c|c|c|c|c|c|c|c|}
\hline & \multirow{2}{*}{$\begin{array}{l}\text { Throat } \\
\text { dia, mm }\end{array}$} & \multirow{2}{*}{$\begin{array}{c}\text { Nozzle } \\
\text { half } \\
\text { angle }\end{array}$} & \multirow{2}{*}{$\begin{array}{l}\text { Area } \\
\text { rat } 10\end{array}$} & \multicolumn{2}{|c|}{ Hydrogen } & \multicolumn{2}{|c|}{ Nitrogen } \\
\hline & & & & $\begin{array}{c}\text { Pressure, } \\
\mathrm{N} / \mathrm{cm}^{2}\end{array}$ & $\begin{array}{c}\text { Flow rate } \\
\mathrm{mg} / \mathrm{s}\end{array}$ & $\begin{array}{c}\text { Pressure, } \\
\qquad / \mathrm{cm}^{2}\end{array}$ & $\begin{array}{c}\text { Flow rate } \\
\mathrm{mg} / \mathrm{s}\end{array}$ \\
\hline Nozzle A & 0.64 & $21^{\circ}$ & 147 & $\begin{array}{l}\mathrm{a}_{10.7} \\
\mathrm{a}_{19.5} \\
\mathrm{a}_{26.8}\end{array}$ & $\begin{array}{r}9.8 \\
19.6 \\
27.1\end{array}$ & $\begin{array}{l}\mathrm{a} 10.4 \\
\mathrm{a} 20.3 \\
\mathrm{a} 26.6\end{array}$ & $\begin{array}{l}38.3 \\
78.6 \\
104\end{array}$ \\
\hline Nozzle B & 2.06 & $20^{\circ}$ & 140,38 & $\begin{array}{l}\mathrm{b}_{0.50} \\
\mathrm{~b}_{1} .01 \\
\mathrm{~b}_{1} .41\end{array}$ & $\begin{array}{r}9.8 \\
19.6 \\
27.1\end{array}$ & $\begin{array}{l}\mathrm{b} 0.55 \\
\mathrm{~b} 1.09 \\
\mathrm{~b} 1.41\end{array}$ & $\begin{array}{l}38.3 \\
78.6 \\
104\end{array}$ \\
\hline $\begin{array}{l}\text { Orifice } \\
\text { plate }\end{array}$ & 0.76 & -- & 1 & $\begin{array}{r}\mathrm{a}_{5.8} \\
\mathrm{a}_{10.0} \\
\mathrm{a}_{13.4}\end{array}$ & $\begin{array}{r}9.8 \\
19.6 \\
27.1\end{array}$ & $\begin{array}{r}a 5.6 \\
a 10.4 \\
a 13.4\end{array}$ & $\begin{array}{l}38.3 \\
78.6 \\
104\end{array}$ \\
\hline $\begin{array}{l}\text { Reference } 2 \\
\text { resistojet }\end{array}$ & 0.47 & $22^{\circ}$ & 37 & $a_{34.5}$ & 6.9 & $a, c 30.4$ & $c_{13.9}$ \\
\hline
\end{tabular}

a line pressure.

${ }^{\mathrm{b}}$ Chamber pressure.

CAmmonia. 


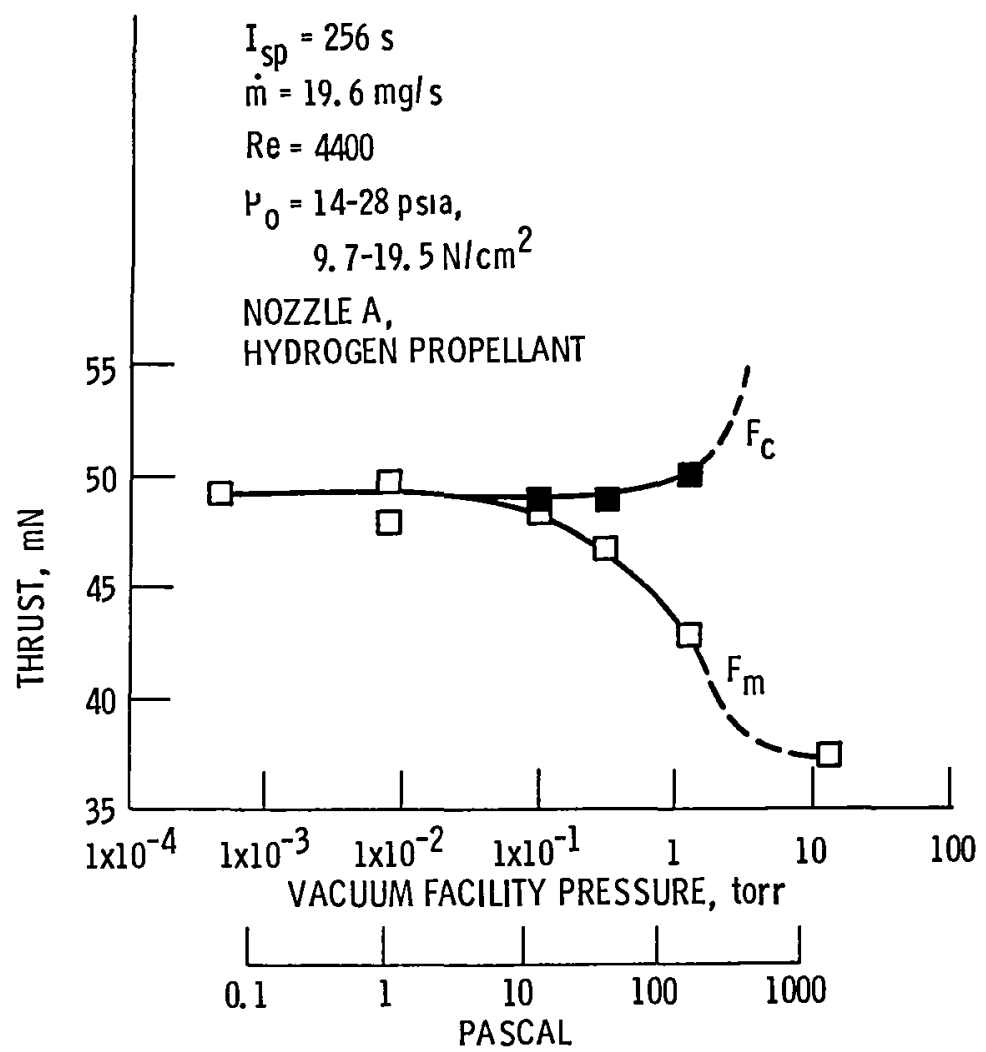

Figure 1. - Typical plot of measured thrust versus vacuum facility pressure.

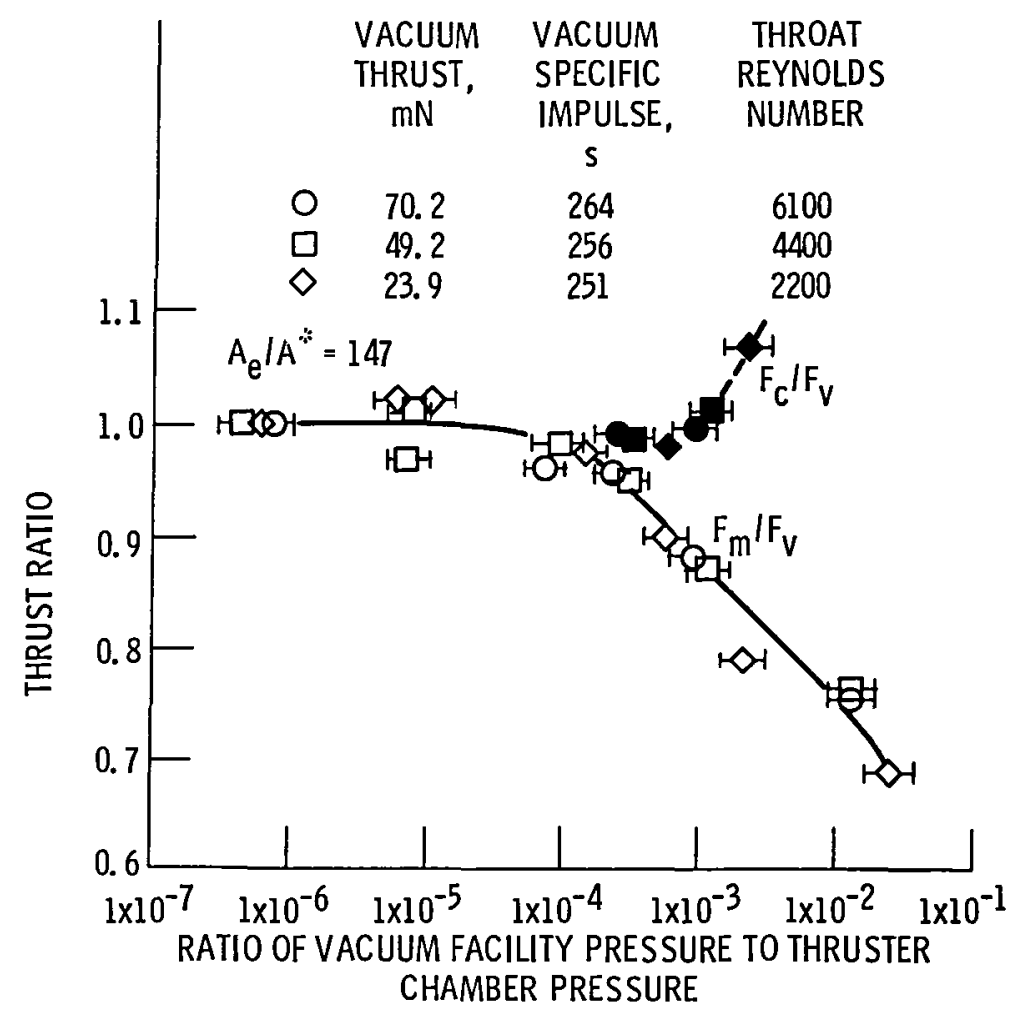

Figure 2. - Effect of vacuum facility pressure on thrust for nozzle A usıng hydrogen. 


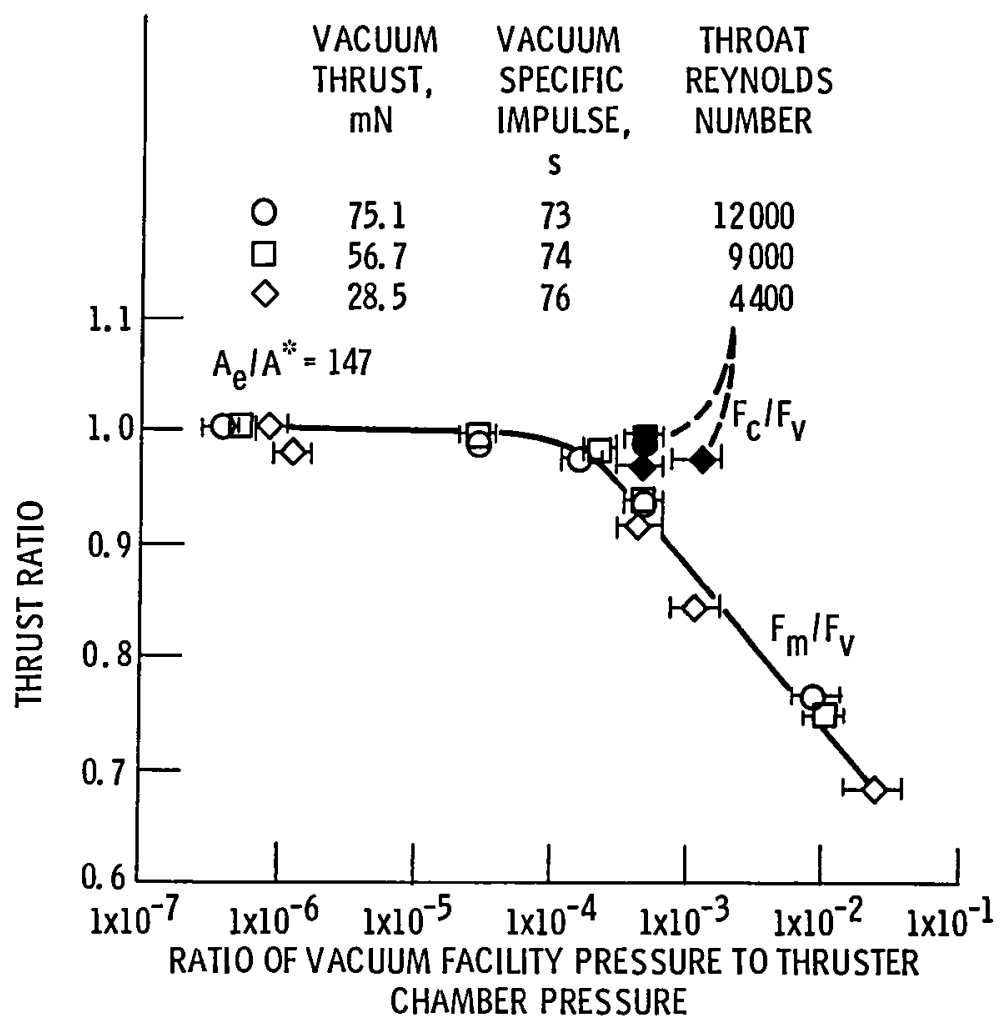

Figure 3. - Effect of vacuum facility pressure on thrust for nozzle A using nitrogen.

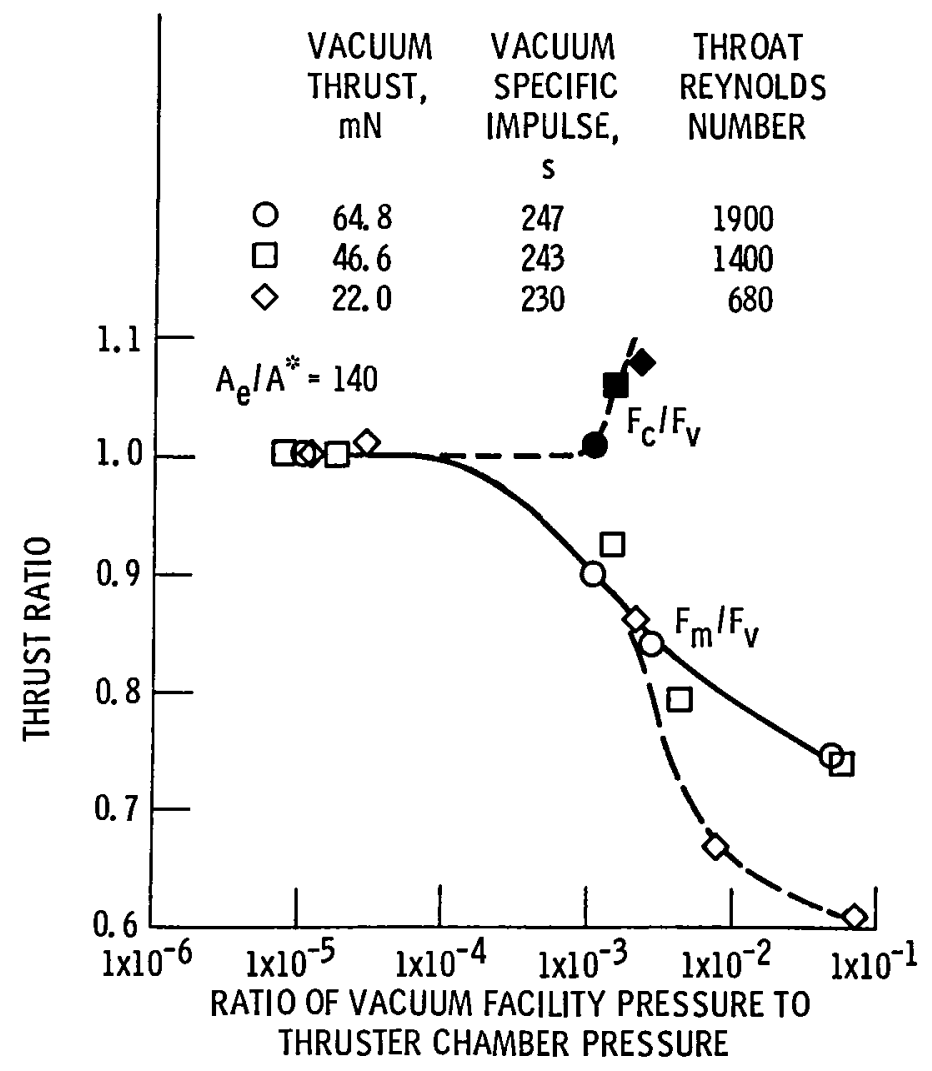

Figure 4. - Effect of vacuum facility pressure on thrust for nozzle $B$ using hydrogen. 


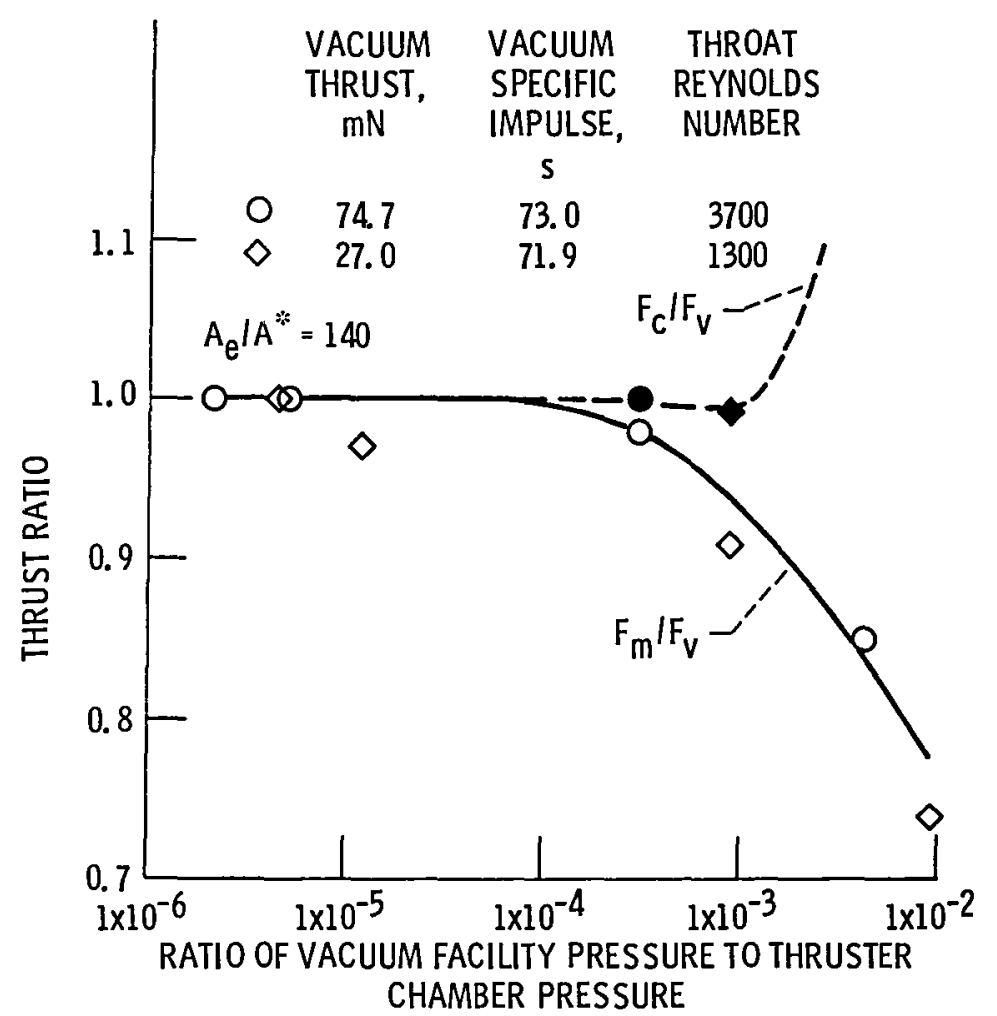

Figure 5. - Effect of vacuum facility pressure on thrust for nozzle $B$ using nitrogen. 


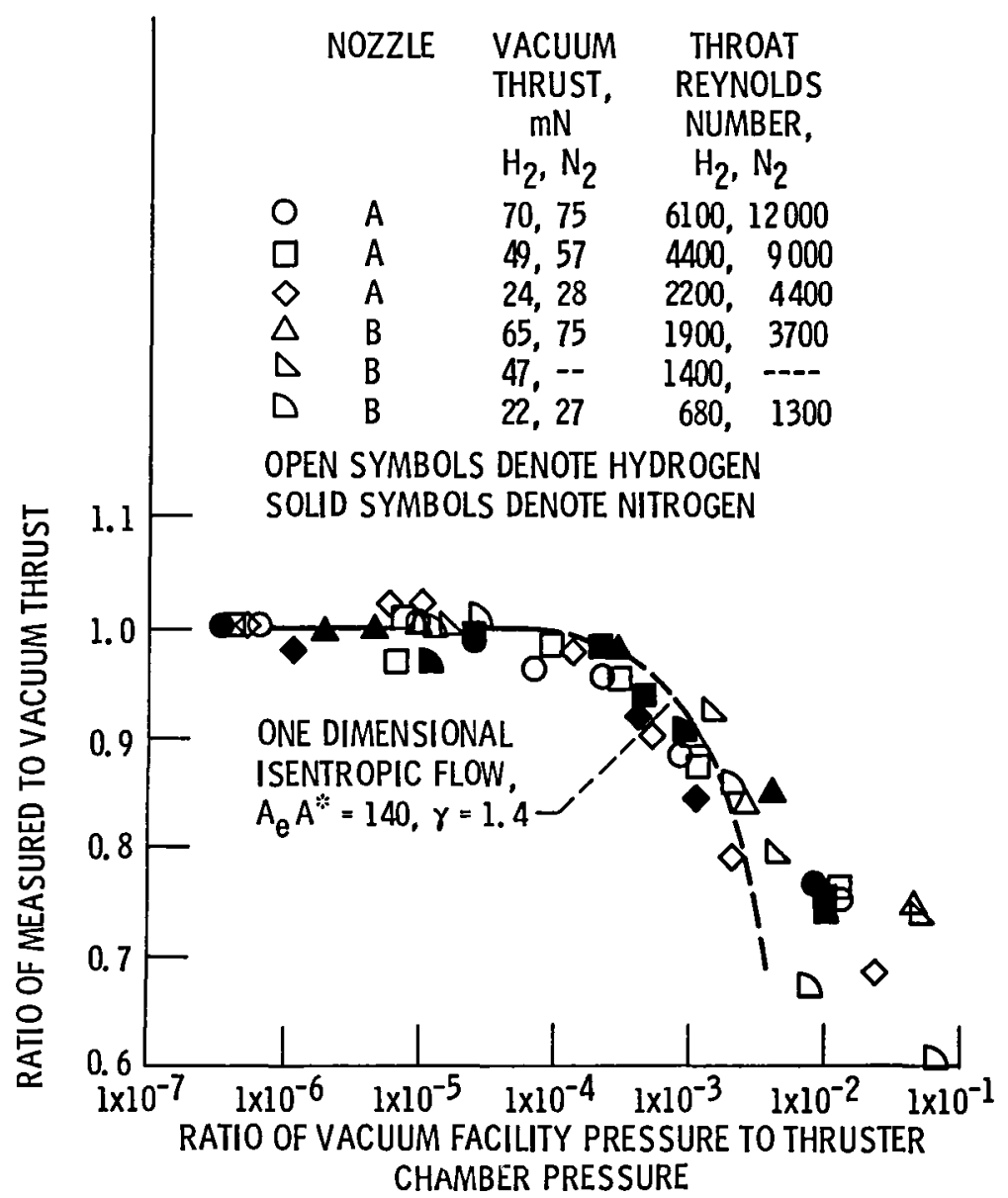

Figure 6. - Comparison of thrust ratio for various thrusters and propellants. 


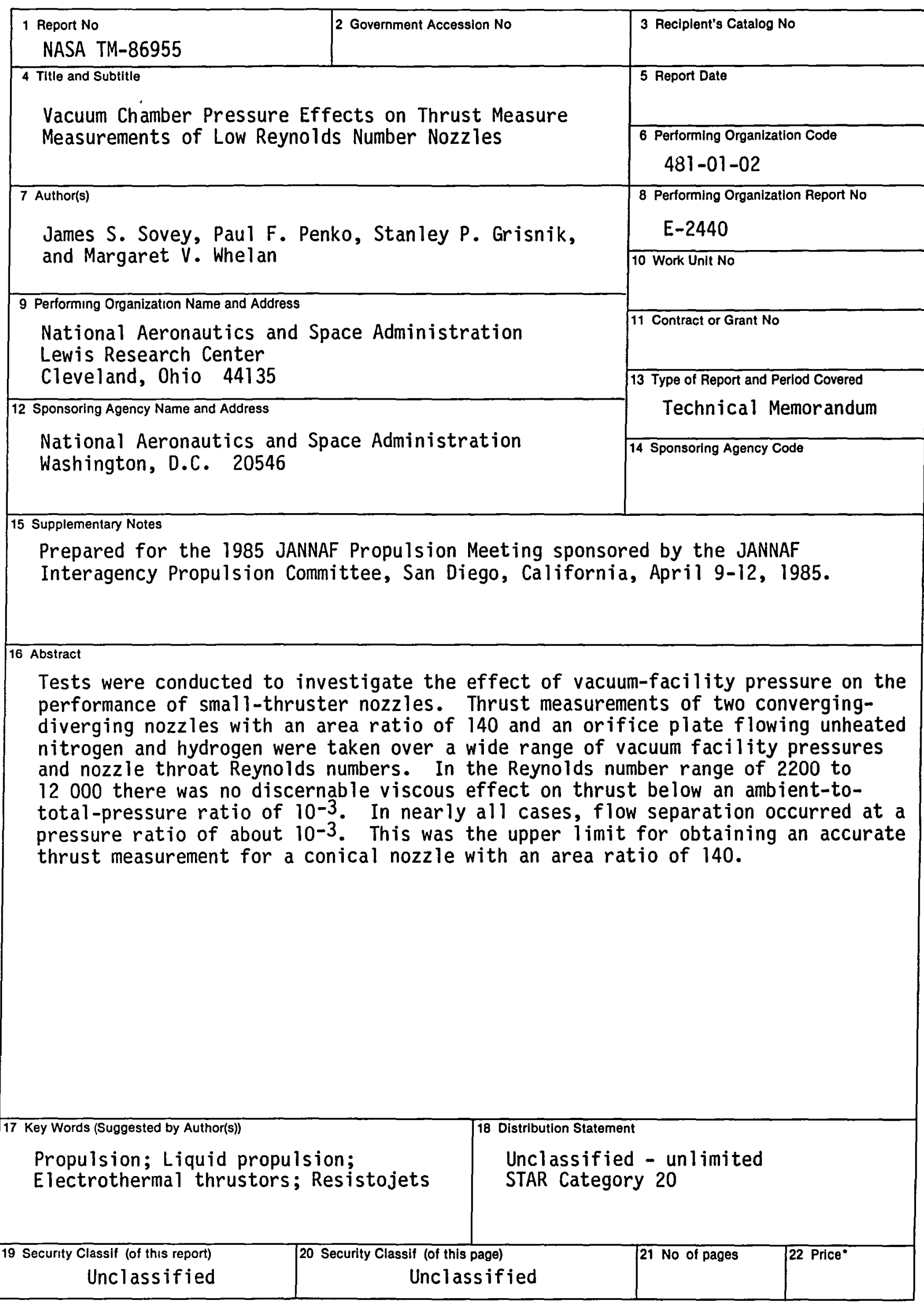

"For sale by the Natıonal Technical Information Service, Springfıeld, Virgını 22161 


\section{End of Document}

